\title{
УДК:575:581.144.2:633.15 https://doi.org/10.53040/gppb7.2021.19 \\ ГЕТЕРОЗИС У КУКУРУЗЫ: К ВОПРОСУ О ПРЕОБЛАДАЮЩЕМ ТИПЕ ВНУТРИЛОКУСНЫХ ВЗАИМОДЕЙСТВИЙ
}

\author{
Михайлов Михаил \\ Институт генетики, физиологии и защитты растений, Кишинэу, Республика Молдова \\ e-mail: mihail.mihailov@igfpp.md
}

\begin{abstract}
Heterosis in maize: toward prevalence type of intralocus interactions. In the biometrical genetic analysis of maize productivity, performed according to the North Caroline III design, unbiased estimates were used to calculate the average degree of dominance, in which, on average, the effect of linkage was eliminated. The hybrids Rf7 $\times \mathrm{Ku} 123$, MK01 $\times$ A619 were studied, and unbiased estimates were calculated for four more hybrids according to the literature data. For genes controlling productivity, unbiased estimates of the average degree of dominance ranged from 0.65 to 0.87 for different hybrids. The result indicates that the heterosis effect in maize is more likely to be caused by dominant interactions than over-dominant ones.
\end{abstract}

Key words: maize, heterosis, quantitative genetics.

\section{Введение}

В вопросе о генетической природе гетерозиса основным спорным моментом является вопрос о преобладающем типе внутрилокусных генетических взаимодействий, от которого зависит выбор между основными теориями гетерозиса - доминирования и сверхдоминирования. Основная причина, по которой сделать этот выбор затруднительно даже сейчас, когда широко применяются методы молекулярного картирования - трудно разделить эффекты сцепленных генов и отличить истинное сверхдоминирование от так называемого псевдосверхдоминирования [4, 7].

В классической биометрической генетике характеристикой внутрилокусных взаимодействий служит средняя степень доминирования, принимающая значения $>1$ при преобладании сверхдоминирования и $\leq 1$ при преобладании доминирования. Однако задача оценки средней степени доминирования решена только для случая несцепленных генов (оценка Комстока-Робинсона) [2]. В случае же сцепления (типичном для такого сложного полигенного признака, как продуктивность) данная оценка проявляет регулярное завышение.

В предыдущей нашей работе разработан способ расчета несмещенной оценки средней степени доминирования, имеющей равную вероятность завышения и занижения при различных вариантах расположения локусов по геному [12]. Для единичного эксперимента данная оценка ненадежна, так как имеет большой разброс, но ее можно применять для ряда экспериментов, выполненных на различном материале. Усредненное по разным экспериментам значение должно адекватно отражать типичную среднюю степень доминирования для данного признака и данного вида. Здесь показаны результаты применения несмещенной оценки как для наших экспериментальных данных, так и для данных, полученными другими авторами.

\section{Материалы и методы}

Исходный материал - гибриды кукурузы Rf7×Ку123 и МК01×A619, из которых производились дигаплоидные (DH) линии. Генетический анализ проводился по экспериментальной схеме СК-3: DHлинии скрещивались с родительскими формами, полученные беккроссы испытывались в полевых условиях. Измерялся ряд количественных признаков, из которых здесь будут рассмотрены общая продуктивность и продуктивность первого початка. Средняя степень доминирования рассчитывалась по дисперсиям между беккроссами по разработанной нами методике [12]. Для расчетов использовались также данные экспериментов по схеме СК-3, проведенных с рекомбинантными инбредными линиями (RIL), полученными из гибридов кукурузы В73×H99, F2×Io, F2×F252, F252×Io [5, 8].

\section{Результаты и обсуждение}

Почти все полученные нами значения средней степени доминирования не превышают единицу, незначительное превышение наблюдалось только у одного значения из 16 (таблица). Это свидетельствует о вероятном преобладании в эффекте гетерозиса доминантных взаимодействий. 
Несмещенные оценки с равной вероятностью могут быть завышенными или заниженными, а вероятность того, что во всех 6 гибридах оценки оказались заниженными, равна 1/64.

Так как не во всех экспериментах учитывались вторые початки, для характеристики продуктивности приводим два показателя: общую продуктивность (со вторыми початками) и продуктивность первого початка. Разница между ними незначительна: у беккроссов вторые початки в благоприятные годы дают прибавку к продуктивности в среднем $10 \%$, но она больше зависит от условий, чем от генотипа, что делает общую продуктивность менее воспроизводимым показателем.

Усредненное значение составляет $0,65 \pm 0,08$ для продуктивности первого початка и $0,76 \pm 0,07$ для общей продуктивности, что соответствует неполному доминированию. Это согласуется с многочисленными наблюдениями о том, что благоприятные аллели редко проявляют полное доминирование и обычно в гетерозиготе их действие несколько ослаблено $[4,7]$. В классическом биометрическом анализе ранее влияние сцепления учитывалось другим способом: для четырех гибридов в схеме СК-3 анализировался материал, прошедший через несколько поколений инбридинга, чтобы разделились многие сцепленные генные пары $[9,10]$. Эти многолетние эксперименты из-за трудности исполнения остались уникальными, и хотя они подтвердили теорию доминирования, но оставалось неясным, насколько результаты для четырех гибридов имеют универсальный характер для всего разнообразия кукурузы. Полученные нами результаты добавляют еще 6 примеров, подтверждающих для кукурузы теорию доминирования.

Таблица. Оценки средней степени доминирования в гибридах кукурузы с поправкой на сцепление

\begin{tabular}{|c|c|c|c|c|}
\hline \multirow{2}{*}{$\begin{array}{c}\text { Гибридная } \\
\text { комбинация }\end{array}$} & Тип популяции & Год (источник) & $\begin{array}{c}\text { Продуктивность } \\
\text { первого початка }\end{array}$ & $\begin{array}{c}\text { Общая } \\
\text { продуктивность }\end{array}$ \\
\hline Rf7×Ку123 & & & 0,99 & - \\
\hline & DH & 2011 & 0,43 & - \\
\hline & DH & 2013 & 0,53 & 0,64 \\
\hline & DH & 2014 & 0,82 & 0,86 \\
\hline & DH & 2015 & 0,60 & 0,11 \\
\hline & DH & 2016 a & 0,36 & - \\
\hline MK01×A619 & DH & 2016 6 & 0,64 & - \\
\hline & DH & 2010 & 0,85 & 0,65 \\
\hline B73×H99 & DH & 2013 & - & 0,64 \\
\hline F2×IL & RIL & Frascaroli et al.,2007 & - & 0,80 \\
\hline F2×F252 & RIL & Larièpe et al., 2012 & - & 0,87 \\
\hline F252×Io & RIL & Larièpe et al., 2012 & - & Larièpe et al., 2012 \\
\hline
\end{tabular}

В настоящее время вопрос о природе гетерозиса остается дискуссионным. Имеет определенное распространение точка зрения, что теория доминирования твердо установлена, по крайней мере для кукурузы. Например, Kaeppler [6], касаясь наблюдавшихся случаев сверхдоминирования в отдельных локусах, отмечает, что «эти и другие неупомянутые здесь примеры свидетельствуют, что сверхдоминирование может участвовать в гетерозисе. Однако на сегодняшний день большинство исследований, основанных на реакции на отбор, разделении генетической дисперсии и картировании QTL, согласуются с меньшей ролью сверхдоминирования, чем доминирования ... Основная масса доступных данных полностью согласуется с гипотезой доминирования как основной причины гетерозиса». Fievete et al. [4] высказываются по тому же поводу следующим образом: «По сравнению с бесчисленными примерами полного или частичного доминирования, хорошо подтвержденные случаи сверхдоминирования остается довольно редкими, и, вероятно, за более чем столетнюю историю генетики было описано менее 20 таких случаев. У кукурузы доминирование, по-видимому, является основным фактором гетерозиса по урожайности и ее компонентам, с умеренной ролью сверхдоминирования и, возможно, эпистаза». По мнению Crow [3] «в настоящее время есть веские доказательства, особенно для кукурузы, что основная часть генетической изменчивости - аддитивная с доминированием, есть измеримый, но небольшой эпистатический эффект. Вклад же сверхдоминирования незначителен или не обнаружили, по крайней мере, для кукурузы».

Ряд авторов высказываются, однако о теории доминирования для кукурузы не как о доказанной, 
а как о весьма вероятной, и склонны объяснять наблюдавшиеся сверхдоминантные эффекты QTL псевдосверхдоминированием, указывая на то, что многие из таких QTL локализованы в прицентромерных зонах, где подавлен кроссинговер. Но такая точка зрения не общепринята. Например, Wang et al. [11] полагают, что в проведенном ими эксперименте на кукурузе обнаружено истинное сверхдоминирование, так как в данном случае изучался эффект хромосомных фрагментов, перенесенных на однородный генетический фон. Но данный вывод не представляется убедительным, так как перенесенные фрагменты довольно длинные, в среднем $9 \mathrm{cM}$, что не позволяет исключить эффекты сцепления. Ряд авторов, например Birchler [1], развивают аргументацию против теории доминирования и ищут альтернативные объяснения гетерозиса.

Таким образом, в настоящее время не существует общепризнанного объяснения гетерозиса, вероятно, от того, что ни одно из объяснений, включая теорию доминирования, не располагает убедительным фактическим материалом в достаточном объеме, и этот вопрос нуждается в дальнейшем исследовании. Полученные нами результаты повышают статистическую обоснованность теории доминирования, увеличивая для кукурузы число подтверждающих ее примеров.

\section{Выводы}

Несмещенные оценки средней степени доминирования, примененные к шести гибридам кукурузы, показали преобладание в эффекте гетерозиса доминантных и полудоминантных взаимодействий с типичной средней степенью доминирования $0,65-0,76$, при этом возможно участие сверхдоминантных взаимодействий в эффекте гетерозиса в качестве второстепенного компонента. Результаты являются аргументом в пользу теории доминирования и дополняют полученные ранее экспериментальные свидетельства, увеличивая с 4 до 10 число примеров, подтверждающих для кукурузы теорию доминирования.

Исследования проведены в рамках проекта Государственной Программы 20.80009.5107.03 «Эффективное использование генетических ресурсов растений и современных биотехнологических методов для повышения адаптивности сельскохозяйственных культур к климатическим изменениям», финансируемой Национальным Агентством по Исследованиям и Развитию Республики Молдова.

\section{Литература}

1. BIRCHLER, J.A. Heterosis: The genetic basis of hybrid vigour. Nature Plants. 2015, 1(3),15020.

2. COMSTOCK, R.H. and ROBINSON, H.F. Estimation of average dominance of genes. Heterosis. Ames, IA: Iowa state college press, 1952. pp. 495-517.

3. CROW, J.F. Mid-century controversies in population genetics. Annual Review of Genetics. 2008(42):1-16.

4. FIÉVET, J.B., NIDELET, T., DILLMANN, C., DE VIENNE, D. Heterosis is a systemic property emerging from non-linear genotype-phenotype relationships: evidence from in vitro genetics and computer simulations. Frontiers in Genetics. 2018, vol. 9, article 159, 26 p. https://www.frontiersin.org/articles/10.3389/fgene.2018.00159/full

5. FRASCAROLI, E., CANÈ, M.A. et al. Classical genetic and quantitative trait loci analyses of heterosis in a maize hybrid between two elite inbred lines. Genetics. 2007, 176(1):625-644.

6. KAEPPLER, S. Heterosis: many genes, many mechanisms - end the search for an undiscovered unifying theory. ISRN Botany. 2012, article ID 682824, 12p. https://www.hindawi.com/journals/isrn/2012/682824/

7. LABROO, M.R., STUDER A.J., RUTKOSKI J.E. Heterosis and Hybrid Crop Breeding: A Multidisciplinary Review. Front. Genet., 24 February 2021. https://doi.org/10.3389/fgene.2021.643761

8. LARIÈPE, A., MANGIN, B. et al. The genetic basis of heterosis: multiparental quantitative trait loci mapping reveals contrasted levels of apparent overdominance among traits of agronomical interest in maize (Zea mays L.). Genetics. 2012, 190(2):795-811.

9. LONNQUIST, J.H. Heterosis: additivity vs. dominance - a corn man's viewpoint. Anales de la Academia Nacional de Ciencias Exactas, Físicas y Naturales de Buenos Aires. 1980, 32:195-202.

10. MOLL, R.H., LINDSEY, M.F., ROBINSON, H.F. Estimates of genetic variances and level of dominance in maize. Genetics. 1964, 49(3):411-423.

11.WANG H., ZHANG X. et al. Identification of heterotic loci associated with grain yield and its components using two CSSL test populations in maize. Scientific Reports. 2016(6), article 38205 https://www.ncbi.nlm.nih.gov/pmc/articles/PMC5395643/

12. МИХАЙЛОВ, М.Э. Учет среднеожидаемого сцепления в биометрическом анализе количественных признаков. Генетика. 2015, 51(8):953-962. 